\section{FOETAL FIBROELASTOSIS}

\author{
BY \\ J. F. HORLEY, M.B., B.S. \\ Assistant Pathologist, Group Laboratory, Royal Sussex \\ County Hospital, Brighton
}

Interest has been aroused from time to time in a cardiac lesion found in infants, the main features of which are thickening and opacity of the lining of the left chambers of the heart. First described as foetal endocarditis in the nineteenth century, it has subsequently been called congenital endocardial sclerosis (Craig, 1949), endocardial dysplasia (Prior and Wyatt, 1950), and endocardial sclerosis (Bonham-Carter et al., 1952), and is now most generally known as fibroelastosis (Weinberg and Himelfarb, 1943). These titles reflect to some extent the changing conceptions of an aetiology which, however, has never been satisfactorily settled.

Recently a disease similar, superficially at least, to fibroelastosis in infancy has been described by several authors, including Bedford and Konstam (1946), Ball et al. (1954), and O'Brien (1954). This has occurred predominantly in natives of the Middle East area, and is characterized post mortem by cardiac enlargement and sclerosis of the endocardium; the possibility that the one may be a late stage of the other has naturally been raised. Already cases previously known as idiopathic cardiac hypertrophy of infancy, in which endocardial thickening may occur, have been linked with fibroelastosis, and this attempt to widen the scope of the disease to embrace all cases showing endocardial sclerosis is attractive. The examination of this problem has been prompted by the occurrence in the last two years in the Brighton Group of Hospitals of three examples of congenital aortic stenosis accompanied by fibroelastosis of the endocardium.

\section{Case 1}

Maternal History.-Aged 27 and in good health; W.R. negative ; Group $O, R h$ positive. She had two healthy children, aged 4 and 7 years; there have been no abortions. Study of the antenatal records and retrospective questioning revealed no illness during the pregnancy; the parents were not blood relations.

The infant, a male, weighed $8 \mathrm{lb} .10 \mathrm{oz}$. $(3.9 \mathrm{~kg}$.) at birth Labour was spontaneous and easy, and his immediate

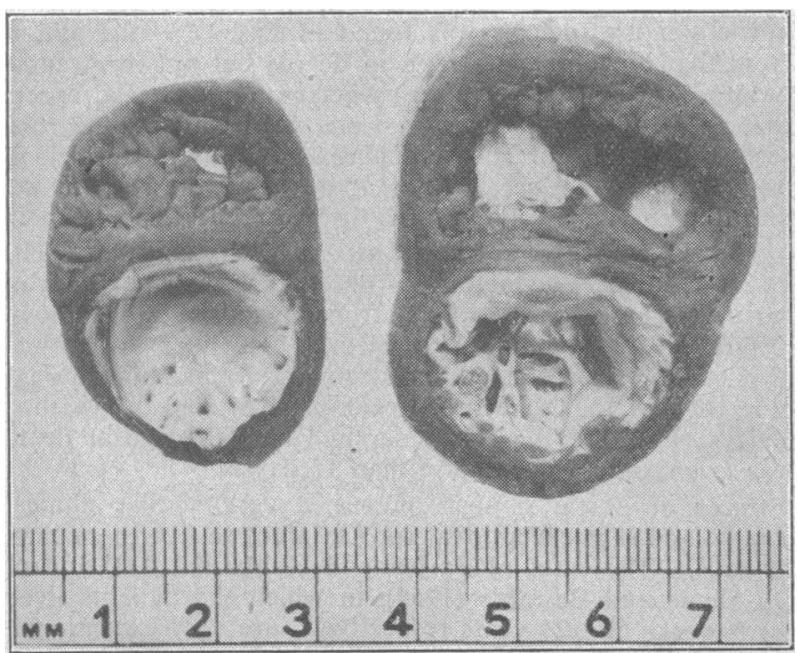

FIG. 1.-Horizontal section through the ventricles. Case 1. recovery was good. On the first day he was observed to be somewhat cyanotic at times, and subsequently respiration became laboured and rapid with frequent cyanotic attacks, in one of which, on the fourth day, he died. No abnormal physical signs had been found during life.

Necropsy.-Complete examination revealed severe venous congestion ; apart from the changes in the heart no developmental or pathological lesion was found.

Heart (Fig. 1).-Weight 25.5 g. Size, apex to base, $4.5 \mathrm{~cm}$.; side to side, $5 \mathrm{~cm}$.; antero-posterior, $3.5 \mathrm{~cm}$. The interventricular groove on the anterior surface ended $0.5 \mathrm{~cm}$. above the apex, which was thus formed from the myocardium of the right ventricle. The right atrium and ventricle were dilated and the latter was also hypertrophied (wall $0.5 \mathrm{~cm}$. thick). The left atrium was normal in size and the left ventricle small. The inner lining of the left ventricle was yellow, tough, and opaque; it measured $0.5 \mathrm{~cm}$. over the interventricular septum and $0.4 \mathrm{~cm}$. elsewhere. The foramen ovale was patent but capable of being closed by a flap-like valve of endocardium. The ductus arteriosus was widely patent and slightly larger than the aorta in diameter. The mitral, tricuspid, and pulmonary valves were natural. The aortic valve was stenosed by fusion of the contiguous borders of the valve cusps, except for a narrow slit between the anterior and left posterior ones.

\section{Case 2}

Maternal Histary.-Aged 27 and in good health; W.R. negative; Group $\mathrm{O}, \mathrm{Rh}$ positive; no immune antibodies in the serum. She had one child, aged $3 \frac{1}{2}$ years, who was healthy, and there had been no abortions. Study of the antenatal records and retrospective questioning revealed no illness during the pregnancy. The parents were not blood relations.

The infant was female and weighed $5 \mathrm{lb} .7 \mathrm{oz} .(2.5 \mathrm{~kg}$.) at birth. Born spontaneously, she appeared well until 2 days old, when she became temporarily dusky in colour and thenceforward suffered from cyanotic attacks ; in one of these, on the fifth day, she died. No abnormal physical signs had been detected during life.

Necropsy.-There was extreme generalized venous congestion; apart from this, complete examination revealed no congenital or pathological lesion except in the heart.

Heart.-Weight $22.5 \mathrm{~g}$. Size, apex to base, $4.5 \mathrm{~cm}$.; side to side, $4 \mathrm{~cm}$.; antero-posterior, $3.5 \mathrm{~cm}$. The interventricular groove on the anterior surface of the heart ended $1.5 \mathrm{~cm}$. above the apex of the heart, which was thus formed by the myocardium of the right ventricle. The right atrium was dilated, the right ventricle dilated and hypertrophied (wall $4 \mathrm{~mm}$. thick); the left atrium was small and the left ventricle vestigial. The endocardium of the left ventricle was tough, yellow, and thickened, especially over the interventricular septum, where it varied from 2 to $3 \mathrm{~mm}$. in thickness. The ductus arteriosus was widely patent and a little larger than the arch of the aorta in diameter. The foramen ovale was patent, but could be closed by an efficient valve-like fold of endocardium. The tricuspid, pulmonary, and mitral valves were natural. The aortic valve was stenosed by fusion of the contiguous borders of the valve cusps, except for a narrow slit between the anterior and left posterior ones ; there was no fibrosis or distortion of the cusps, which remained thin and pliable. The coronary arteries were normal in origin, structure, and distribution.

\section{Case 3}

Maternal History.-Aged 20 and in good health; W.R. negative; Group $\mathrm{O}, \mathrm{Rh}$ negative, with no immune antibodies in the serum. She had had no previous children, abortions, or blood transfusions. Retrospective questioning and perusal of the antenatal records revealed no illness during the pregnancy. The parents were not blood relations.

The infant, a male, weighed $5 \mathrm{lb} .12 \mathrm{oz}$. $(2.6 \mathrm{~kg}$.) at birth ; blood Group $\mathrm{O}, \mathrm{Rh}$ positive. $\mathrm{Hb}$ at birth $16.3 \mathrm{~g}$. per $100 \mathrm{ml}$., direct Race-Coombs test negative. The day after birth he was observed to be dusky-coloured at times. 
Cyanotic attacks thereafter became frequent, and on the eighth day he died in one of them. No abnormal physical signs had been detected during life.

Necropsy.-There was severe systemic venous congestion, but apart from this no congenital or pathological lesion was found other than that of the heart.

Heart.-Weight $17.3 \mathrm{~g}$. Size, apex to base, $4.4 \mathrm{~cm}$.; side to side, $4 \mathrm{~cm}$.; antero-posterior, $3.4 \mathrm{~cm}$. The interventricular groove on the anterior surface ended $1.6 \mathrm{~cm}$. from the

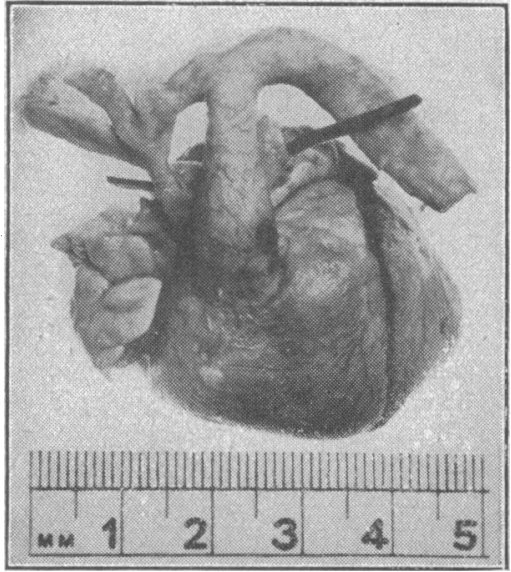

Fig. 2.-Arrangement of the great vessels in Case 3. apex of the heart, which was formed by the myocardium of the right ventricle: The right atrium was dilated, the right ventricle dilated and hypertrophied (wall 4 mm. thick). The left atrium was small and the left ventricle vestigial. The lining of the left ventricle was opaque, tough, and yellow - wh it e, especially over the in terven tricular septum, where it was $3 \mathrm{~mm}$. thick. The columnae carneae were absent. The foramen ovale was widely patent, but could be closed by a flap-like valve of endocardium. The arrangement of the great vessels is shown in Fig. 2. The ductus arteriosus was patent, $6 \mathrm{~mm}$. in diameter, and the same size as the arch of the aorta. The ascending aorta was $2 \mathrm{~mm}$. only in diameter and there was no communication between it and the left ventricle. The aortic valve was closed by complete fusion of the valve-cusp borders. It was $2 \mathrm{~mm}$. in diameter, and when viewed from the aortic side presented three distinct pits defined by three ridges meeting at the centre and corresponding to the edges of the aortic valve cusps. The coronary arteries arose opposite the anterior and left posterior depressions and were distributed normally; they were fed by retrograde blood-flow down the ascending aorta, which served no other purpose. The tricuspid and pulmonary valves were natural, the mitral small but not stenosed.

\section{Microscopy}

Sections were taken from the myocardium, opaque endocardium, aortic valve cusps, and coronary arteries in each case: the microscopical appearances were similar in all, so that their description may be combined.

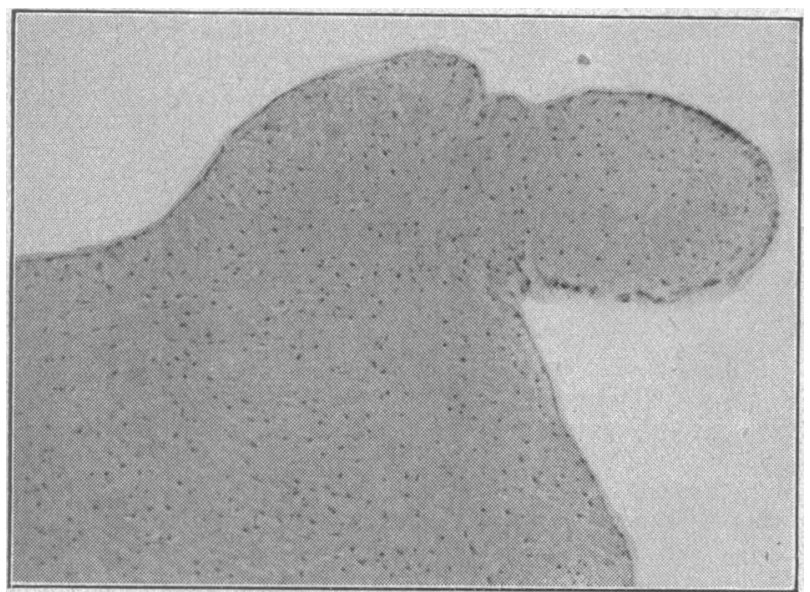

Fig. 3.-Section at point of fusion of an aortic valve cusp. $(\times 95$.
Section of the coronary arteries taken at $0.5-\mathrm{mm}$. intervals revealed no constriction of lumen or abnormality of the wall. The aortic valve cusps showed some increase in volume, made up by interlacing bundles of collagen undergoing oedematous change. In no case was there inflammatory cell infiltration; in particular, section at the point of fusion of valve cusps (Fig. 3) showed no scar tissue.

The myocardium was normal, with no inflammatory cell aggregates or fibrosis. The junction between the myocardium and the opaque endocardium was irregular and ill-defined, and in places islands of myocardial fibres were surrounded by tongures of fibrous tissue (Fig. 4). Many of the myocardial fibres were degenerate in the junctional layer and were being replaced by fibroblasts. The bulk of the opaque endocardium was composed of normal collagen fibres, but

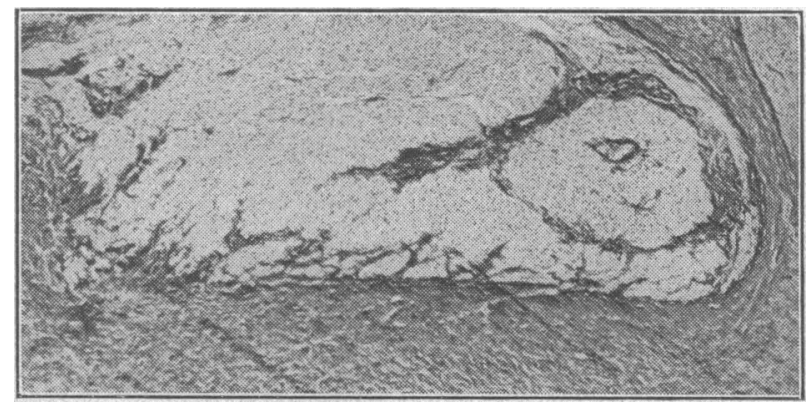

Fig. 4.-Section at point of junction between the myocardium and the endocardium. $(\times 55$.

when stained with orcein and eosin a high proportion of elastic fibres were found. A feature of the junctional layer was a large number of thin-walled dilated blood vessels.

\section{Discussion}

Aortic atresia is a rare condition. Canton (1948-9) appears to have been the first to report a case, and since then 20 others have been traced-those of Shattock (1881), Summons (1906), Gauss (1916), Fraser (1921), Mueller (1924), Abbott (Loose-Leaf Medicine), Schrader (1928), Philpott (1928), Willer and Beck (1932) two cases, Bellet and Gouley (1932), Farber and Hubbard (1933), Wesson and Beaver (1935), Roberts (1936), Rossman (1942), Craig (1949) four cases, and Halliday (1954). Case 3 reported here is thus the 22 nd recorded example. In addition to aortic atresia, all showed a hypoplastic left ventricle lined by an opaque, white, thickened endocardium with an intact interventricular septum. The appearance of the aortic atresia is striking, and descriptions exactly similar to that given in Case 3 are repeatedly encountered. It is evident that the valve cusps have developed regularly and then fused along their borders, for, macroscopically, there is usually no distortion of pattern and microscopically no evidence of fibrosis. Incomplete aortic stenosis such as was found in Cases 1 and 2 differs from that of complete atresia in degree but not in essential nature. Fusion of valve cusps occurs as in atresia, except that a slit may be left between one pair, while endocardial sclerosis is constant and hypoplasia of the left ventricle is usually found. It seems likely that atresia and stenosis are both the end-result of the same disease process.

The clinical pattern of aortic atresia is very constant. The infant 'recovers satisfactorily from the immediate' stress of parturition and then suffers from cyanosis and difficult respiration 12-36 hours after birth. Usually no abnormal physical signs are elicited and death occurs at about 5 days old. Out of the 22 recorded examples, 14 died in less than 6 days, while, of the remainder in which the age at death was given, only 3 lived more than 15 days.

Cases of aortic stenosis pursue a very similar clinical course, and it is exceptional for an infant to live more than 14 days. The cases of Farber and Hubbard (1933) and of Du Shane and Edwards (1954), in which the patients lived for 9 weeks and $2 \frac{1}{2}$ years respectively, are very exceptional, but both appeared to have had typically fused valve cusps. 
Recent literature on fibroelastosis gives the impression that this change may occur at any age from birth to 5-6 years of age, and that valvular stenosis may or may not be associated in any particular example. However, study of available case reports and photographs shows that the occurrence of aortic stenosis is by no means haphazard. The heart weights and times of death when stated in all the patients under 9 months old accepted by Gowing (1953) in a recent review of the subject are arranged in Fig. 5; added to these are

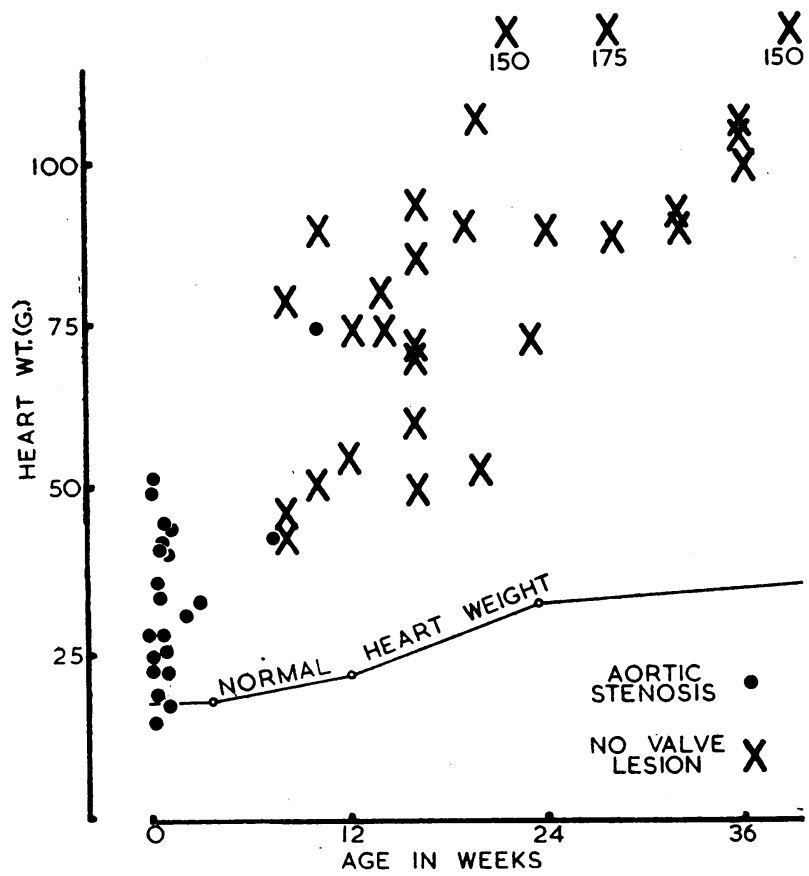

Fig. 5.-Cases of foetal and infantile fibroelastosis contrasted.

all cases of aortic stenosis or atresia which could be traced. It is apparent from this that fibroelastosis in infancy is capable of division into two groups which are in many ways contrasted.

One group, which is referred to as foetal fibroelastosis and which is represented by the three cases described in this paper, is characterized by aortic stenosis (sometimes accompanied by mitral stenosis), early death, and relative or absolute hypoplasia of the left ventricle; the heart weight is only moderately increased and is accounted for by right ventricular hypertrophy. The other group, many cases of which had been described previously as idiopathic cardiac hypertrophy of infancy, is without valvular lesions and is referred to as infantile fibroelastosis. The left ventricle is grossly hypertrophied and usually dilated, and it accounts for heart weights three to five times the normal; death is uncommon under 3 months old, and it is interesting that fibroelastosis without valvular stenosis has not been recorded at birth except in the case described by Prior and Wyatt (1950). The latter would be an interesting exception, but, since it is given no separate description and there is no photograph, it is of doubtful value. Fibroelastosis of the endocardium is common to both groups, but the gross thickening found in foetal cases is seldom seen in infantile fibroelastosis : in some of the descriptions and photographs of the latter it is so slight that it raises the question of hr,w far the term should be stretched.

\section{Aetiology}

Gross (1941) effectively rejected intrauterine inflammation as an explanation for the changes found in foetal fibroelastosis. Subsequently maternal infection and mesenchymal dysplasia have been popular hypotheses, but neither has evidence to support it. However, the microscopical appearances have many features in common with those found in endocardial fibrosis overlying adult cardiac infarction. The irregular junctional line and dilated vessels, the occasional report of lymphocytic aggregates and calcification, and the evident fibrous replacement of the myocardial fibres bordering the endocardium are all similar and suggest that anoxia may be common to both. The main difference between the two is lack of fibrosis in the myocardium outside the junctional layer in foetal fibroelastosis. An explanation of this may lie in the way in which the anoxia is caused.

For a considerable time in utero, until the coronary circulation is fully established, the foetal heart is dependent for nourishment on blood flowing through its cavities. During this period temporary closure of the foramen ovale during the course of its development, along the lines suggested by Johnson (1952), would prevent oxygenated blood in the right atrium from flowing into the left atrium and left ventricle, and this may cause degeneration of the endocardium covering the aortic or mitral valves. In the absence of sufficient blood flow to keep them apart, fusion of the raw edges of the cusps would be expected with little fibrosis or distortion. If aortic stenosis was established in this way, stenosis and consequent anoxia of the blood in the left ventricle would occur and lead to degeneration of the layer of myocardium lining the cavity and the development of the fibrosis found in foetal fibroelastosis. Naturally, the myocardium outside the area supplied from within the cavity would be unaffected and normal in appearance. All the changes found in foetal fibroelastosis would thus be explained.

Support for this hypothesis is found in the rare examples of aortic and mitral atresia accompanied by ventricular septal defects. For example, Dolgopol (1934) described a heart with aortic atresia in which the vestigial left ventricle communicated with the right through a narrow slit : the left ventricular cavity was lined by normal endothelium. One of Halliday's (1954) cases showed mitral atresia and multiple ventricular septal defects. Fibroelastosis was found in the left atrium but not in the left ventricle. If both aortic stenosis and fibroelastosis were the result of mesenchymal dysplasia the presence of an interventricular septal defect would not influence the development of the latter. On the other hand, if fibroelastosis is the result of stasis and anoxia of blood in the left ventricle the change would not occur if oxygenated blood were available from the right ventricle through a septal defect. In fact, no case of aortic atresia has been traced in which fibroelastosis has occurred accompanied by an interventricular defect, and, conversely, no case of aortic atresia with an intact interventricular septum was without fibroelastosis.

Detailed discussion of the aetiology of infantile fibroelastosis does not come within the scope of this paper. However, the rarity of its occurrence within the first two months of life makes a developmental defect of embryonic origin unlikely, and an explanation bringing it into line on the basis of anoxia may be found with further research.

A connexion between cases of foetal fibroelastosis and the group described in adults is most unlikely, for the latter have no valvular defects, while the former all appear to die at a very early age. It is still possible that cases of infantile fibroelastosis may develop into the adult group, but at the moment the gap in age between the two is formidable. An explanation which seems more acceptable is that both are caused by a similar and as yet unknown mechanism.

\section{Summary}

Three cases of fibroelastosis accompanied by aortic stenosis or atresia are described.

Study of these cases and of other published reports shows that fibroelastosis in the first year of life may be divided clearly into two groups for which the terms foetal and infantile fibroelastosis are suggested. The first, manifest at birth, is characterized by early death, aortic stenosis, left ventricular hypoplasia, and right ventricular hypertrophy. The second, usually not 
covered until 3 months of age or more, has no valvular defects and shows very considerable increase in heart weight due to gross left ventricular hypertrophy.

On morphological grounds anoxia of the cardiac muscle during cardiac development seems to offer the most acceptable explanation of the changes found at post-mortem examination in foetal and infantile fibroelastosis, and a possible mechanism for this is offered.

The connexion between foetal and infantile fibroelastosis and the endocardial sclerosis found in adults is discussed.

I should like to thank Dr. W. A. Bourne for his advice and encouragement during the preparation of this paper. I wish to thank also Miss M. K. Lawlor and Dr. J. F. Enright for permission to report on patients admitted under their care. Mr. Jackson very kindly photographed the specimens.

\section{REFERENCES}

Abbott, M. E. Nelson Loose-Leaf Medicine, 4, 307. Nelson, New York. Ball, J. D., Williams, A. W., and Davies, J. N. P. (1954), Lancet, 1, 1049. Bedford, D. E., and Konstam, G. L. S. (1946). Brit. Heart J., 8, 236. Bellet, S., and Gouley, B. A. (1932). Amer. J. med. Sci., 183, 458. Bonham-Carter, R. E., Swyer, P. R., and Pugh, R. C. B. (1952), Lancet, 1. 311 .

Canton (1848-9). Trans. Dath. Soc. Lond., 2, 38.

Craig, J. M. (1949). Bull. Int. Ass. med. Mus., 30, 15.

Dolgopol, V. B. (1934). J. techn. Meth., 13, 100.

Du Shane. J. W., and Edwards, J. E. (1954). Proc. Mayo Clin., 29, 102.

Farber, S., and Hubbard, J. (1933). Amer. J. med. Sct., 186, 705.

Fraser, A. (1921). Proc. N.Y. path. Soc., 21, 91

Gauss, H. (1910). Amer. J. Dis. Child., 12, 606.

Gowing, N. F. C. (1953). J. Path. Bact., 65, 13.

Gross, P. (1941), Arch. Path. (Chicago), 31, 163.

Halliday, W. R. (1954), Dis. Chest, 26, 27.

Johnson, F. R. (1952). Arch. Path (Chicago), 54, 237.

Mueller, B. (1924). Virchows Arch. path. Anat., 249, 368

O'Brien, W. (1954). British Medical Journal, 2, 899.

Philpott, N. (1928). Ann. intern. Med., 2, 422.

Prior, J. T., and Wyatt, T. C. (1950). Amer. J. Path., 26, 969.

Roberts, J. T. (1936), Amer. Heart J., 12, 448.

Rossman, J. I. (1942), Amer. J. Dis. Child., 64, 872

Schrader, G. (1928). Zbl. allg. Path. path. Anat., 42, 5.

Shattock, S. G. (1881). Trans. path. Soc. Lond., 32, 38.

Summons, W. F. (1906). Intercolon. med. J. Aust., 11, 65.

Weinberg, T., and Himelfarb, A. J. (1943). Bull. Johns Hopk. Hosp., 72, 299.

Wesson, H. R., and Beaver, D. C. (1935). J. techn. Meth., 14, 86

Willer, H., and Beck, L. (1932). Z. KreislForsch., 24, 633.

"There is at present a sickness in our country-a sickness of rumour and anxiety, of suspicion and distrust, and, at its worst, of fear and tragedy," said Dr. Weaver, President of the American Association for the Advancement of Science, in his introductory remarks to the address of the retiring president (Science, February $\cdot 18,1955$ ). Analysing the causes of this sickness, Dr. Weaver blamed the lack of "constructive courage with respect to the future," the strange lack of faith in scholarly competence, and the misguided zeal of sincere persons with mistaken ideas of good citizenship. At its worst the disease was "the result of political pressure, of personal selfishness, and of the pathological demagogs with small and nasty minds." The effect of these general and recurring fears was that confidence in government promises and even in the "Anglo-Saxon tradition of due process" had been destroyed. Commenting on the universality of this sickness, Dr. Weaver pointed out that science voiced its concern at it, not to demand protection for itself, but primarily because the problem was a universal one. As a remedy he called for the abandonment of timidity, and in its place a " really sensible, constructive stand," giving the warning that wit and patience must be used because "freedom is too precious to deserve rash or stupid support." $\mathrm{He}$ hoped that government concern " to improve the whole loyalty-security-secrecy setup" was a sign that the sickness of his country was waning, and at that actual meeting they were celebrating a " rededication to liberal decency."

\section{SOME EFFECTS OF HIGH-ALTITUDE} CLIMBING

\section{INVESTIGATIONS MADE ON CLIMBERS OF THE BRITISH KANGCHENJUNGA RECONNAISSANCE EXPEDITION, 1954}

BY

\section{STAFFORD MATTHEWS, M.B., F.R.C.S.Ed. M.R.C.O.G., F.R.G.S. \\ Medical Officer to the Expedition; Calcutta}

\section{B.. P. TRIBEDI, M.B., Dip.Bact., F.N.I.}

A. R. ROY, M.B.

Department of Pathology, Medical College, Calcutta

\section{R. CHATTERJEE, D.I.C.}

AND

A. GHOSAL, B.Sc.

Department of Chemistry, Medical College, Calcutta

During the 1954 British Kangchenjunga Reconnaissance Expedition the opportunity was taken of carrying out certain biochemical and microscopical analyses of blood and urine samples obtained by the expedition medical officer (D. S. M.) from climbers at various altitudes. These were sent by runners to Darjeeling and dispatched by aeroplane to the Medical College, Calcutta, for assessment. Although many expeditions to the Himalayas have been made, there has unfortunately been little scientific liaison between them. We understand that samples of blood were collected from climbers of the successful 1953 Everest Expedition and sent back to England for analysis. We have not seen the results of those analyses or of any investigations that may have been conducted by other parties. Referable literature is difficult to obtain.

\section{General Observations}

A significant feature worth noting in relation to this expedition was the fact that it was primarily a reconnaissance. Knowing this, the party would be less likely to experience the anxiety stresses that are often associated with the anticipation of future efforts required in attempting to reach the summit. It is usually only at levels above those reached on this expedition that the almost inevitable deterioration occurs, no matter what degree of acclimatization is simultaneously taking place.

Our approach to Kangchenjunga was along the Singalila ridge - a high-level route throughout - which, although relatively arduous, must have been responsible for the high degree of acclimatization attained by all members of the party when base camp $18,000 \mathrm{ft}$. $(5,500 \mathrm{~m}$.) was reached on the eighteenth day out. No climber suffered from headache, nausea, or undue breathlessness except that three members experienced occasional spells of characteristic rapid periodic breathing. Sore throat and gastro-enteritis were rare, and there were no cases of frost-bite. Some of the porters who did not wear sunglasses complained of photophobia, and a mild conjunctivitis was found on examination. It was a revelation to watch some of the porters, barefooted, carry loads through snow and ice, and sleep at night in the open with scanty clothing-such is their ability to acclimatize to cold. The sherpanis-we had 16 of these female porters-performed their duties as well as most of the men.

Rothera tests were performed on numerous occasions on the mountain, particularly after climbers had made 